\title{
Assessment of the Outcome of an Educational Programme of Diabetes Self-care
}

\author{
M.P.Beggan, D.Cregan and M.I. Drury \\ Diabetes/Endocrine Unit, Mater Misericordiae Hospital, Dublin, Ireland
}

\begin{abstract}
Summary. The efficacy of our current educational programme for diabetic patients was assessed. Cognitive and behavioural tests were administered to 75 Type 1 (insulin-dependent) diabetic patients, aged $\leqslant 30$ years attending the Diabetic Clinic of the Mater Misericordiae Hospital, Dublin, Ireland. An overall deficiency in knowledge was evident. Fifty-one patients responded incorrectly to $>20 \%$ of the items tested. Twenty-nine patients lacked the ability to communicate a simple understanding of diabetes. Whereas most $(70+)$ correctly identified the methodology of urinalysis, uncertainty was evident concerning appropriate action needed in response to such tests. Forty-nine did not know the significance of thirst and polyuria and 20 were unaware that hyperglycaemia could
\end{abstract}

progress to coma. The ability to modify insulin dosage was poor as was the ability to use exchanges. Of patients aged $\geqslant$ 20 years, those from the Dublin region scored better than did those from surrounding towns or rural areas, $(r=0.5 ; p<$ $0.01)$. Regular out-patient attenders scored less well than nonattenders $(r=0.24 ; p<0.05)$ but had better glycosylated haemoglobin levels $(r=0.3 ; p<0.01)$. Gycosylated haemoglobin showed no significant correlation with level of knowledge held.

Key-words: Assessment, educational programme, diabetic self-care, Type 1 diabetes, $\mathrm{HbA}_{1}$, socio-demographic influences.
The management of diabetes mellitus, whilst under the overall control of the physician, demands the active participation of the patient, the degree of this participative role being determined by the willingness and the capacity of the patient to co-operate.

A prerequisite is that the patient accepts the diagnosis and learns how to administer the required regime. Patient education is, therefore, of fundamental importance. Such training involves cognitive elements and behavioural skills, e.g. diet, self-medication and selfmonitoring. The better the patient's understanding of the essential nature of diabetes and of the therapeutic goal, the more likely he is to be motivated to accept the regime and to persevere in its long-term implementation [1]. Thus, an effective educational programme is an essential part of a diabetic unit.

At the Mater Misericordiae Hospital, Dublin, Ireland, an educational programme was designed by one of us (MID) 30 years ago and since then has been modified in response to experience. All newly registered patients (newly diagnosed or new referrals) are instructed on a one-to-one basis by nurse instructors and dietitians using an instruction manual written by the medical director, a nurse instructor and a dietitian. Newly diag- nosed Type 1 (insulin-dependent) diabetic patients receive initial instruction as in-patients and instruction continues at out-patient sessions. Since 1977 a Day Centre, staffed by three nurse instructors and a dietitian, has been functioning as a teaching centre and as a provider of supervision and support, particularly for young diabetic patients. Details of the programme can be obtained from the authors on request.

This paper reports the evaluation undertaken to determine the effectiveness of this programme, to identify its deficiencies and to suggest appropriate changes in approach and methodology. The focus is on the outcome rather than on the process and is concerned with the degree to which diabetic patients have assimilated essential cognitive and behavioural elements after a period of instruction and self-care. Examination of major socio-demographic factors likely to influence receptivity to educational inputs is also undertaken. Others have demonstrated that diabetic patients display numerous errors in both knowledge and skills when tested [2-12] and attempts at evaluating educational programmes have indicated their limited effectiveness $[10,12]$. Age and duration of diabetes have been examined in relation to knowledge and the results have been inconclusive $[4,9,12]$. 


\section{Patients and Methods}

The study population comprised all Type 1 diabetic patients (aged $\leqslant$ 30 years) who attended one of us (MID) at the Mater Hospital for the first time during an 18 month period from January 1976 to June 1977. The data were collected during the first half of 1980 , ensuring that all patients had been on treatment for a minimum of $2 \frac{1}{2}$ years. The study cohort comprised 48 males and 38 females. A further six were excluded from consideration. Three were mentally retarded and three were $<8$ years old.

The data collection consisted of four distinct elements.

(1) A checklist of 95 items of knowledge was drawn up covering the following areas; (a) general information about Type 1 diabetes; (b) methodology of urine testing; (c) care and hygiene; (d) hypoglycaemia; (e) hyperglycaemia; (f) insulin; (g) manipulation of insulin dosage; (h) diet. With the advice of staff involved in teaching, acceptable responses to each item were defined. The level of knowledge expected was set at the minimum standard acceptable to instructors. The questionnaire was administered by the researcher (MB) on a one-to-one basis in all but eight cases, who completed forms at home after instructions over the telephone. This ensured uniformity in its administration and allowed clarification of meaning where necessary. Correct answers were given a value of one and all other answers were assigned a zero value.

(2) A checklist of behavioural skills was drawn up dealing with injection preparation and administration, urinalysis techniques and use of dietary exchange lists. Definitions of minimally acceptable levels of competence were drawn up to facilitate scoring, as already described. As these items were assessed in behavioural terms, personal attendance was necessary. Details of the items included in the cognitive and behavioural tests, together with response requirements, are available from the authors on request.

(3) Patients were interviewed by the researcher using a schedule dealing with socio-demographic variables.

(4) All patients had a detailed physical examination and a blood glucose profile during or within 6 months of this study. Means of preceding blood glucose levels over the years were calculated and glycosylated haemoglobin $\left(\mathrm{HbA}_{1}\right)$ was measured once, at the time of interview.

The cognitive items were divided to form indices under the eight sections previously defined. Each index was categorised into three grades of knowledge according to the proportion of correct answers in each section, i.e. 'excellent' - $100 \%$ correct answers in an index; 'moderate' $\geqslant 80 \%$ but $<100 \%$ correct and 'poor' $<80 \%$ correct. Each respondent was assigned a score for each of the eight sections

Table 1. Response rates from cohort of 86

\begin{tabular}{ll}
\hline & No \\
\hline Test of knowledge and interview schedule & 75 \\
Test of skill & 65 \\
Blood glucose profile & 65 \\
Physical examination & 70 \\
\hline
\end{tabular}

and the scores were then aggregated. This final score determined the final placement category, i.e., excellent, moderate or poor.

A variable, indicating core knowledge, was developed by selecting from the original 95 items, 55 items considered to be vital and this indicator was used in analyses of the socio-demographic variables.

The final response rates varied with the elements of the research (Table 1). In any analysis of interrelationships between variables those lacking the required information were omitted. Statistical analyses were carried out using chi-square and Pearson's correlation coefficient.

\section{Results}

The distribution of scores under the various headings are detailed in Table 2 and elaboration of these findings follow.

\section{Overall Knowledge}

This heading indicates aggregate scores and 51 (over two-thirds) respondents fell within the 'poor' category.

\section{General Understanding}

A minimum basic understanding of the nature of Type 1 diabetes was sought, the objective being to establish the ability of patients to define for themselves and for others, in lay terms, the nature of diabetes. All such questions were answered correctly by $46(61.3 \%)$ respondents.

\section{Urinalysis}

This index covered not only the technique of urinalysis but also tested the patient's understanding of the need for urinalysis, their capacity to interpret the results and take appropriate action. Only $16(21.3 \%)$ gave wholly correct answers. More detailed analysis disclosed that most patients knew the importance of urinalysis (74), how often to test (74), how to read the results correctly (73) and how to care for the equipment (70). However, $15(20 \%)$ patients were uncertain about the action to be taken if heavy glycosuria persisted for 3 consecutive days and $28(37.3 \%)$ were uncertain about the indications for the acetone test. Only $29(39 \%)$ patients knew the significance of persistent acetonuria and $18(24 \%)$

Table 2. Patients' Level of Knowledge: Scores in Relation to Overall Knowledge and Individual Sections

\begin{tabular}{|c|c|c|c|c|c|c|c|c|c|c|c|c|}
\hline Score & $\begin{array}{l}\begin{array}{l}\text { Overall } \\
\text { knowledge }\end{array} \\
(n=75)\end{array}$ & $\begin{array}{l}\text { General } \\
\text { under- } \\
\text { standing } \\
(n=75)\end{array}$ & $\begin{array}{l}\text { Urinalysis } \\
(n=75)\end{array}$ & $\begin{array}{l}\text { Care and } \\
\text { hygiene } \\
(n=75)\end{array}$ & $\begin{array}{l}\text { Hypo- } \\
\text { glycaemia } \\
(n=75)\end{array}$ & 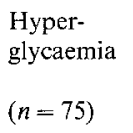 & $\begin{array}{l}\text { Insulin - } \\
\text { general } \\
(n=75)\end{array}$ & $\begin{array}{l}\text { Insulin - } \\
\text { alteration } \\
(n=75)\end{array}$ & $\begin{array}{l}\text { Dietary } \\
(n=75)\end{array}$ & $\begin{array}{l}\text { Urin- } \\
\text { alysis } \\
\text { skills } \\
(n=64)\end{array}$ & $\begin{array}{l}\text { Insulin } \\
\text { skills } \\
(n=64)\end{array}$ & $\begin{array}{l}\text { Dietary } \\
\text { skills } \\
(n=66)\end{array}$ \\
\hline $\begin{array}{l}\text { Excellent } \\
(100 \%)\end{array}$ & $1 \quad(1.3)$ & $46(61.3)$ & $16(21.3)$ & $30(40.0)$ & $32(42.7)$ & $31(41.3)$ & $8(10.7)$ & $20(26.7)$ & $29(40.0)$ & $11(17.2)$ & $38(59.4)$ & $21(31.8)$ \\
\hline $\begin{array}{l}\text { Moderate } \\
(\geqslant 80 \% \\
<100 \%)\end{array}$ & $23(30.7)$ & $15(20.0)$ & $25(33.3)$ & $25(33.3)$ & $21(28.0)$ & $11(14.7)$ & $51(68.0)$ & $9(12.0)$ & $39(50.7)$ & $45(70.3)$ & $17(26.6)$ & - \\
\hline $\begin{array}{l}\text { Poor } \\
(<80 \%)\end{array}$ & $51(68.0)$ & $14(18.7)$ & $34(45.3)$ & $20(26.7)$ & $22(29.3)$ & $33(44.0)$ & $16(21.3)$ & $46(61.3)$ & $7 \quad(9.3)$ & $8(12.5)$ & $9(14.0)$ & $45(68.2)$ \\
\hline
\end{tabular}

Figures in parentheses $=$ percentage 
failed to appreciate the importance of double voiding. Each respondent was asked to perform urinalysis under supervision with the observer noting 12 elements, e.g., timing, recording, interpretation. Only $11(17.2 \%)$ performed perfectly whilst eight $(12.5 \%)$ were correct in < $80 \%$ of these items. Glucose testing was performed and read correctly by 64 but four failed to appreciate the significance of the results. The test for acetonuria was performed and read correctly by $55(86 \%)$ patients but 52 $(83 \%)$ misinterpreted the result.

\section{General Care and Hygiene}

This index dealt with foot care, exercise and intermittent illness and $30(40.0 \%)$ answered all questions correctly. Detailed analysis showed that although almost all $(90 \%+)$ could detail the system of foot care, 18 (24\%) did not understand the need for such care, a probable reflection on the lack of explicit reference to diabetic complications during instruction. All but four were aware that exercise lowered the blood glucose, yet 14 did not appreciate the risk of exercise before a meal or the need to take extra carbohydrate before unusual exercise. The likely elevation of the blood glucose during illness or infection was unknown to 14 and 10 did not know whether insulin should be continued at such times.

\section{Hypoglycaemia}

Whereas $32(42.7 \%)$ patients answered all of these questions correctly, the nature of an insulin reaction was unknown to 10 patients and 12 were unable to describe the common symptoms. Most could specify corrective measures (73) and precipitating causes (70). Nineteen did not appreciate that irritability might be an indication of hypoglycaemia and 23 were unaware that hypoglycaemia might arise even if urinalysis showed heavy glycosuria.

\section{Hyperglycaemia}

This test assessed, in particular, awareness of the symptoms indicating loss of control and of the procedures to be followed in such a circumstance. All questions were answered correctly by $31(41.3 \%)$ but as many as 49 (52\%) did not know the significance of thirst and polyuria and 20 were unaware that uncorrected hyperglycaemia might progress to coma.

\section{Insulin - General}

Questions in this index dealt with insulin regimes, injection technique, current dosage and care of syringes. Only eight respondents answered all questions correctly. Whereas dosage and strength of insulin were known by most, $21(28 \%)$ were uncertain of the appropriate syringe and relied on the pharmacist's choice.
Thirty-eight (52\%) were unaware of the procedure to follow if insulin was 'lost' during the injection. The ability to perform the injection correctly was assessed by asking patients to inject under supervision. The task was broken into six elements and 38 (59.4\%) performed perfectly. Deficiencies were most likely to arise in insulin loading and in the identification and selection of sites with $18(28 \%)$ and $11(17 \%)$, respectively, failing to carry out these tasks correctly.

\section{Insulin Alteration}

Specific questions were designed to assess capacity to modify insulin dosage without consultation - an important aspect of effective self-care. Each respondent was asked to identify the urine test which should be used as a guide to the effect of each insulin used and to state the basis upon which the dose should be modified. A once or twice daily insulin mixture was used by $57 \mathrm{pa}-$ tients and a further 18 used a single insulin once or twice daily. All questions relevant to their insulin regime were answered correctly by $20(27 \%)$. Only 30 $(40 \%)$ knew the peak action times of their various insulins. Paradoxically, the more complex the insulin regime, the greater was the level of understanding of insulin manipulation $(\mathrm{r}=0.5 ; \mathrm{p}<0.0001)$.

\section{Dietary Knowledge}

Recognising the complexity of dietary management, this study concentrated on the identification of foods by main categories, i.e., protein, carbohydrate and fat and their relevance to the diabetic programme. Sixty-five $(87 \%)$ understood the importance of dietary control. Carbohydrate foods were correctly identified by 61 $(81 \%)$, whilst $50(67 \%)$ identified protein and $40(53 \%)$ fats. Sixty-two $(83 \%)$ could indicate times at which it would be appropriate to increase food intake. Seventeen $(23 \%)$ did not understand the use of exchanges. Dietary skills were tested under supervision by asking respondents to make substitutions for various carbohydrate items on their allocated diet pattern. Forty-five $(68 \%)$ were unable to do so.

\section{Core Knowledge}

The scores for core knowledge ranged between 23 and 55 , with a mean of $47.2(\delta=6.5)$. This distribution was sub-divided into three rank-ordered categories to create a relatively even distribution amongst the ranks (Table 3). As the maximum age of our respondents was 30 years, the effect of age on knowledge was minimized and is reflected in the non-significant relationship found. The distribution by sex was relatively even and although no significant correlation emerged between sex and level of knowledge, relatively more males than females demonstrated a low level of knowledge. The fe- 
Table 3. Level of core knowledge and socio-demographic variables

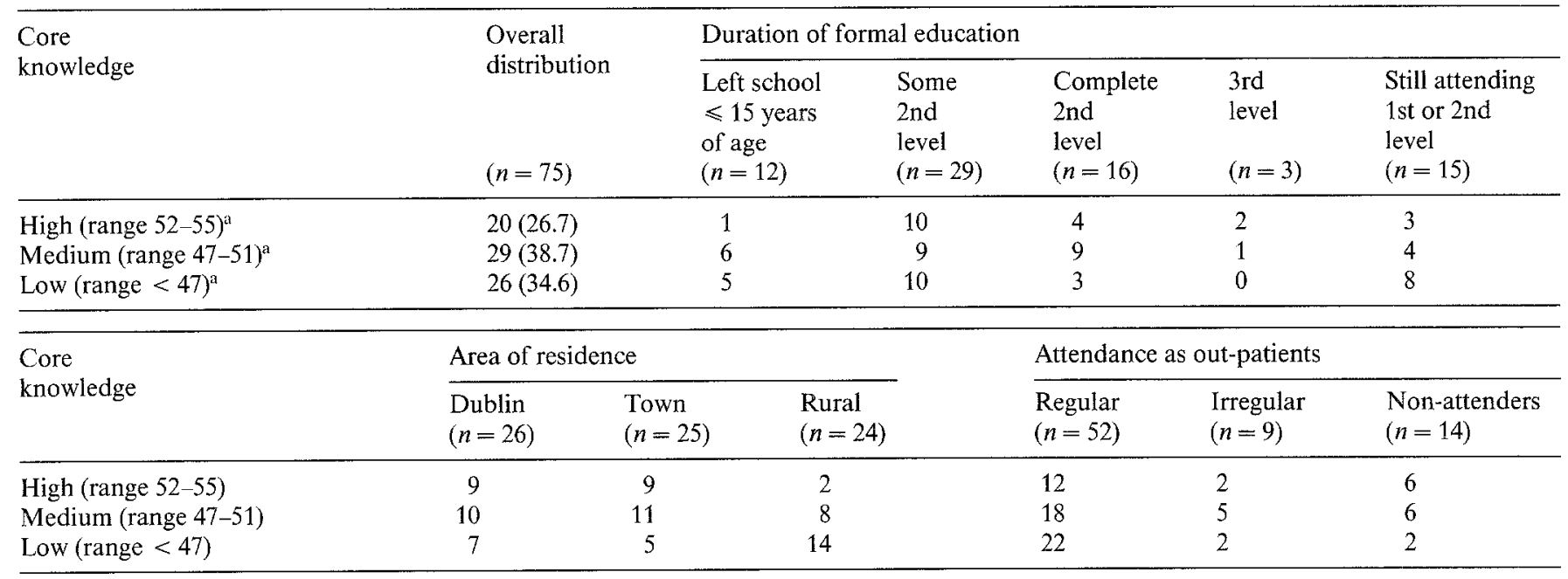

"Figures in parentheses $=$ percentage

male respondents had diabetes for longer than the males $(r=0.34 ; p<0.001)$.

Duration of formal education was ranked, broadly, from the minimum legal school-leaving age (15 years), through second-level, which ranges between 15 and 18 years, to participation in full-time education after that age and this variable correlated significantly with level of knowledge $(r=0.22 ; p<0.05$; Table 3$)$. In this instance, those still attending first or second level education were not included in the statistical analysis but are represented in Table 3. Patients were categorised by area of residence as being from the Dublin region, smaller towns or rural areas and this was found to be significantly associated with level of knowledge ( $r=$ $0.33 ; p<0.001$; Table 3 ). There was a tendency for rural dwellers to have a lower level of core knowledge than those from Dublin. However, when age was allowed for there was no significant correlation for those $<20$ years but for those $\geqslant 20$ years $(\mathrm{n}=46)$ the correlation increased sharply $(r=0.5 ; p<0.01)$. When duration of formal education was examined in relation to this finding, it was not found to affect the correlation significantly. It is of note that $36(48 \%)$ patients travelled distances of $>50$ miles on visits to the Diabetic Clinic.

Socio-economic categories were examined using an adaptation of the Hall + Jones Scale of Occupational Prestige to the Irish population [13]. The spread amongst the eight-point ordinal scale was relatively even and was not significantly associated with degree of core knowledge held. Neither was duration of diabetes significantly related to knowledge.

Respondents were coded according to the regularity of their attendance as out-patients since they first attended in 1976. Those who attended at the normal, recommended interval (6 monthly or under) were regarded as 'regular' attenders; those attending less than 6 monthly but at least yearly were regarded as 'irregular' attenders and those attending less than yearly were classified as 'non-attenders'. Whereas all young Type 1 diabetic patients are asked to attend at least 6 monthly, those considered to be poorly controlled are asked to attend more frequently. A significant correlation was found when frequency of attendance was examined in relation to level of core knowledge $(r=0.24 ; p<0.05$; Table 3), indicating a tendency for those who attend most frequently to have the lowest level of knowledge. When the original comprehensive test of knowledge was related to frequency of attendance, this pattern was confirmed $(r=0.3, p<0.01)$. When age and area of residence were taken into account, this correlation was not significantly affected.

The current study used two measures of diabetic control - a mean of blood glucose results and $\mathrm{HbA}_{1}$ estimations. Neither correlated significantly with core knowledge (Table 4). However, $\mathrm{HbA}_{1}$ results did correlate significantly with regularity of attendance at the Diabetic Clinic $(r=0.3 ; p<0.01)$, indicating better control amongst regular clinic attenders.

\section{Discussion}

An overall deficiency in knowledge is evident amongst this cohort. As 29 patients lacked the ability to retain and communicate a simple understanding of diabetes, there is an obvious need to convey more information of a general nature. The timing of such instruction must take into account the possible lack of receptivity to information after the trauma of initial diagnosis [14]. At the time of undertaking our evaluation, home blood glucose monitoring did not form part of management practice but is now used by many of our patients. Encouragement and instruction is now given on the use of the available methods. Unpublished data from our sur- 
Table 4. Level of core knowledge, $\mathrm{HbA}_{1}$ scores and mean blood glucose level

\begin{tabular}{|c|c|c|c|c|c|c|}
\hline \multirow[t]{2}{*}{ Core knowledge } & \multicolumn{3}{|c|}{$\begin{array}{l}\mathrm{HbA}_{1} \text { Score }(\%) \\
\text { Normal range }(7.0 \%-9.5 \%)\end{array}$} & \multicolumn{3}{|c|}{ Mean blood glucose level $(\mathrm{mmol} / \mathrm{l})$} \\
\hline & $\begin{array}{l}\leqslant 9.5 \\
(n=15)\end{array}$ & $\begin{array}{l}>9.5<11.5 \\
(n=31)\end{array}$ & $\begin{array}{l}\geqslant 11.5 \\
(n=19)\end{array}$ & $\begin{array}{l}\leqslant 8.5 \\
(n=33)\end{array}$ & $\begin{array}{l}>8.5 \leqslant 10.5 \\
(n=21)\end{array}$ & $\begin{array}{l}>10.5 \\
(n=11)\end{array}$ \\
\hline High (range 52-55) & 5 & 9 & 2 & 12 & 2 & 1 \\
\hline Medium (range 47-51) & 4 & 14 & 8 & 11 & 10 & $\hat{7}$ \\
\hline Low $($ range $<47$ ) & 6 & 8 & 9 & 10 & 9 & 3 \\
\hline
\end{tabular}

vey indicated that $51 \%$ of respondents held negative attitudes towards the usefulness of urinalysis and our findings showed that although the methodology of urinalysis was well understood, many patients were uncertain of the action to be taken in response to the results. Thus, urinalysis may be viewed as a ritualistic practice or as information to be collected for interpretation at the clinic rather than as a guide to self-management. Increased emphasis must, therefore, be placed on the importance of urinalysis (or home blood glucose monitoring) as an essential tool of self-management.

The inability to modify insulin dosage was disappointing and indicates a superficial level of understanding of self-management. The degree to which patients can regulate their own insulin, under the overall care of the physician, reflects their capacity for self-care. Amongst the young such ability should be fostered, whilst at the same time avoiding the creation of situations in which patients may regard themselves as selfsufficient and independent of clinic supervision. It appears that diets are unnecessarily restricted due to inability to use exchanges and that encouragement should be given to make full use of suitable food stuffs - for if the recommended diet allows much variety, compliance will be more likely.

Of interest was the finding that adult patients from the Dublin area were better informed than those from small towns and rural areas. This relationship was found to be significant in four of the eight areas of knowledge - hypoglycaemia, insulin, insulin alterations and diet. Duration of formal education was not significantly associated with area of residence and it is unlikely that intellectual capacity would be a factor. Although explanations may be posited in terms of cultural or social differences, we suggest propinquity or ease of access to the Diabetic Centre as a likely explanation for this finding. Although regularity of attendance was not significantly associated with area of residence, relative ease of access to the resources and particularly to the staff of the centre, is likely to encourage communication and thus act as a motivator and a facilitator of learning. Some support for this explanation may be taken from the study by Deckert et al. [15] of patients attending a clinic in Copenhagen. Here it was found that those living in the city had a better prognosis than those living in towns or in rural areas and the authors suggested that the better access to therapy and supervision amongst city patients was responsible for this difference. If ease of access to a diabetic centre is, indeed, related both to prognosis and to knowledge of self-management, programmes of positive discrimination in favour of those living at a distance from diabetic centres are indicated.

The inverse relationship found between regularity of attendance as out-patients and level of core knowledge, a relationship confirmed in six of the eight areas of knowledge, raises serious questions about the quality of service given at the out-patient clinic, particularly in relation to the benefits of attendance as perceived by well informed patients. Whereas our educational facilities have improved in recent years, our out-patient facilities remain over-crowded and consultations, therefore, rushed. Improved knowledge does not necessarily bring with it improvements in diabetic control. Williams et al. [3] found that although knowledge correlated positively with performance of recommended regimes, it correlated negatively with control. The fact that there was a tendency for better control, as determined by $\mathrm{HbA}_{1}$, amongst those attending the clinic at the recommended interval of 6 months and that $\mathrm{HbA}_{1}$ was not significantly correlated with knowledge, reinforces the advisability of maintaining regular contact with the physician and strongly indicates the need to develop consultatory, supportive out-patient facilities.

The problem of improving our educational programme remains. Based on this evaluation, explicit learning objectives will be established and a system of continuous re-assessment, following and initial baseline assessment of knowledge, will be implemented. Increased emphasis will be placed on staff development in relation to teaching and evaluation skills. However, the complex interrelationships between patient knowledge, regime performance and control must be acknowledged, reminding us that improvements in methods of education do not necessarily result in better diabetic control.

\section{References}

1. Strauss A (1975) Chronic illness and the quality of life. C. G. Mosby, St. Louis, pp 21-27

2. Etzwiler DD (1962) What the juvenile diabetic knows about his disease. Paediatrics 29: 135-141 
3. Williams TF, Martin DA, Hogan MD, Watkins JD, Ellis EV (1967) The clinical picture of diabetic control, studied in four settings. Am J Pub Health 57: 441-451

4. Watkins JD, Williams TF, Martin DA, Hogan MD, Anderson E (1967) A study of diabetic patients at home. Am J Pub Health 57: $452-459$

5. Etzwiler DD, Robb JR (1972) Evaluation of programmed education among juvenile diabetics and their families. Diabetes 21: 967-971

6. Nickerson D (1972) Teaching the hospitalized diabetic. Am J Nursing 72: 935-938

7. Watkins JD, Moss FT (1969) Confusion in the management of diabetes. Am J Nursing 69: 521-524

8. Etzwiler DD, Simes LK (1972) Juvenile diabetes and its management: family social and academic implications. JAMA 81: 304-308

9. Miller LV, Goldstein J, Nicholaison G (1978) Evaluation of patients' knowledge of diabetes self-care. Diabetes Care 1: 275-280

10. Whitehouse FW, Whitehouse IJ, Smith J, Hohl RD (1979) Teaching the person with diabetes: experience of a follow-up session. Diabetes Care 2: 35-38

11. Alleyne SL, Morrison EY St A, Richards RR (1979) Some social factors related to control of diabetes mellitus in adult Jamaican patients. Diabetes Care 2: 401-408

12. Lawrence PA, Cheely J (1980) Deterioration in diabetic patients' knowledge and management skills as determined during outpatient visits. Diabetes Care 3:214-218

13. MacGréil M (1977) Prejudice and tolerance in Ireland. College of Industrial Relations, Dublin, pp 594-600

14. Hoover J (1979) The view from the other side. Diabetes Care 2: $448-450$

15. Deckert T, Poulsen JE, Larsen M (1978) Prognosis of diabetics with diabetes onset before age of thirty-one. 11. Factors influencing the prognosis. Diabetologia 14:371-377

Received: 26 October 1981

and in revised form: 5 March 1982

Dr. M. I. Drury

Diabetes/Endocrine Unit

Mater Misericordiae Hospital

Dublin 7, Ireland 